\title{
O Ensino Contextualizado de Interações Intermoleculares a partir da Temática dos Adoçantes
}

\section{The Contextualized Teaching of Intermolecular Interactions based on the Topic of Sweeteners}

\author{
Mayara de Carvalho Santos ${ }^{1}$ \\ Larissa Rocha Almeida ${ }^{1}$ \\ Pedro Faria dos Santos Filho ${ }^{1}$ \\ 'Universidade Estadual de Campinas (Unicamp), Instituto de Química, Campinas, SP, Brasil. \\ Autora correspondente: m190982@dac.unicamp.br
}

Resumo: As discussões sobre as mudanças necessárias nos livros já são há muito conhecidas. Contudo, essa mudança não pode ser feita de uma hora para outra; é preciso que, aos poucos, novos materiais auxiliares sejam produzidos para ajudar nesse processo de transição entre modelos de livros. Em vista disso, construímos uma Unidade Didática Temática Contextualizada, que visa auxiliar o professor no ensino de Interações Intermoleculares a partir do processo de percepção do sabor doce. O presente artigo analisa os resultados da aplicação dessa unidade em uma disciplina de química para a graduação. Os resultados mostram que os alunos não só aprenderam os conceitos químicos, mas que utilizaram o fenômeno do sabor doce para explicá-los. Além disso, os alunos aprenderam algumas características da ligação hidrogênio, comumente ignorada nos livros didáticos. Concluímos que a contextualização realmente ocorreu e atuou como uma abordagem efetiva no processo de ensino-aprendizagem.

Palavras-chave: Ensino e aprendizagem; Ensino superior; Ensino de química; Livro didático; Contextualização.

Abstract: Discussions about the necessary changes in textbooks have long been known. However, this change cannot be sudden. Gradually, it is necessary produce new auxiliary material to help this transition process between textbook models. Therefore, we have built a contextualized, thematic didactic unit, which aims to assist the teaching of intermolecular forces based on the process of perception of sweet taste. This article analyzes the results of the application of this unit in an undergraduate class. The results show that students not only learned the chemical concepts but also used the sweet-taste phenomenon to explain the interactions. In addition, students learned features such as the linearity of the hydrogen bond, commonly ignored in textbooks. We conclude that the contextualization was truly fulfilled and functioned as an effective approach in the teachinglearning process.

Keywords: Teaching and learning; Higher education; Chemistry education; Textbooks; Contextualization.

Recebido em: 10/06/2019

Aprovado em: 04/03/2020 


\section{Introdução}

O mau desempenho nas provas do Exame Nacional de Desempenho dos Estudantes (ENADE) dos concluintes dos cursos de licenciatura e bacharelado em Química no país escancara a realidade da má formação de nossos professores. As médias do exame variaram entre 13 e 33,5 em uma escala de 0 a 100 (BRASIL, 2017a). Ao não formarmos bons professores para atuarem no Ensino Médio, pode-se compreender que nossos estudantes também não terão uma boa formação. Este fato pode ser constatado pelo Índice de Desenvolvimento da Educação Básica (IDEB) para o Ensino Médio, que tinha como meta a pontuação de 4,7 para o ano de 2017, todavia a média nacional atingiu apenas 3,8 (BRASIL, 2017b).

Diante desse cenário, o governo federal propôs mudanças com a publicação das Diretrizes Curriculares Nacionais (DCN) e dos Parâmetros Curriculares Nacionais (PCN). Essencialmente, esses documentos devem ser orientadores curriculares para aqueles envolvidos com a educação nacional, e definem como princípios organizadores a contextualização e a interdisciplinaridade (BRASIL, 2000, 2013).

A contextualização começou a ser pensada em um momento onde os conteúdos escolares eram apresentados de forma isolada e fragmentada de seus contextos originais, chegando ao aluno de forma reproduzida, abstrata e sem sentido (KATO; KAWASAKI, 2011). Essas discussões não são novas e a importância da contextualização para o ensino é bem aceita. Entretanto, a ideia de contextualização vem tomando diferentes interpretações, notando-se que não há um consenso.

Lopes (2002) e Ricardo (2005) argumentam que há ambiguidade na concepção de contextualização segundo os PCN. Os Parâmetros indicam que a educação deve ser voltada para a vida. Contudo, o entendimento deles sobre vida relaciona-se frequentemente com a inserção no mundo produtivo, ao mesmo tempo em que usam argumentos construtivistas para reforçar a necessidade de um ensino contextualizado.

Diferentes noções são encontradas não apenas nos documentos oficiais, mas também entre professores (KATO; KAWASAKI, 2011; SILVA; MARCONDES, 2010) e entre os próprios elaboradores do Exame Nacional do Ensino Médio (ENEM) (FERNANDES; MARQUES, 2012). Kato e Kawasaki (2011) destacam que essas interpretações derivam de concepções de contexto diversas. Outro exemplo é apresentado nos resultados de Silva e Marcondes (2010) apontando que, dentre os níveis de contextualização do ensino, a maioria dos professores entende a contextualização como simples exemplificação de fatos do cotidiano.

Assim, a concepção de contextualização não é única, porém, nos arriscamos a dizer que há algo em comum entre elas: a ideia de relação e conexão. Independentemente do que se entende por contexto ou do aprofundamento que se dá a ele, a contextualização parece ser entendida como a criação de relações entre os saberes formais e informais, portanto, conectando-os.

Essa, portanto, é a nossa interpretação do que seria contextualizar o ensino. Nossa concepção de contextualização toma como contexto as vivências do aluno e sua realidade mais próxima, pois é nela que o aluno está imerso, constrói sua visão de mundo e a si mesmo. Para nós, o objetivo de contextualizar o ensino vem antes de capacitar o aluno para o trabalho, possibilitando que ele se desenvolva cognitivamente. 
Em vista disso, tomamos a teoria de Vygotsky como referencial, especialmente no que diz respeito à interdependência existente entre os conceitos cotidianos e científicos (VYGOTSKY, 1995). Segundo esse autor, os conceitos científicos requerem o desenvolvimento de capacidades de generalização e abstração, e isso ocorre a partir de funções psicológicas mais simples, típicas dos conceitos espontâneos. Assim, entendemos a contextualização como um caminho para a construção de relações entre esses dois tipos de conceitos.

Podemos adaptar essas ideias para a química. A contextualização do ensino de química, portanto, tem a função de melhorar a aprendizagem dos conceitos científicos, contribuindo para o desenvolvimento intelectual dos alunos. Todavia, a aprendizagem de conceitos mais complexos como os científicos exige a mediação do professor. Ou seja, o professor deve estar capacitado a reconhecer aquilo que o aluno já sabe para criar relações com o conteúdo de química, de forma que os conceitos científicos tenham significado dentro da vivência cotidiana do aluno.

Diante do exposto, a formação dos professores, em especial os de química, tornase essencial para o desenvolvimento dos estudantes. Entretanto, conforme os índices colocados no início desse artigo, a formação docente ainda precisa melhorar muito no Brasil. Pesquisadores da área vêm discutindo o assunto e alguns estudos oferecem alternativas que podem contribuir para a formação dos professores.

Amorim, Souza e Trópia (2010) discutiram a influência de um curso de formação continuada para a prática de uma professora de química. Segundo os autores, após o curso, a professora conseguiu produzir uma sequência didática contextualizada sobre aquecimento global que culminou em melhor desempenho de seus alunos. Desta forma, percebe-se que a formação mais adequada pode propiciar melhora no ensino.

Outras pesquisas optam por instrumentalizar o professor, oferecendo sequências didáticas prontas para serem aplicadas em sala de aula. Lima et al. (2000) mostraram como os alunos enriqueceram suas respostas após uma intervenção didática sobre o uso de aditivos na conservação de alimentos.

Em outras propostas, os autores buscaram alternativas para as deficiências no ensino propondo novos materiais didáticos. É o caso de Medeiros e Lobato (2010) que analisaram a forma como o conteúdo de radiações é abordado em livros de química e física. Os autores elaboraram um material didático complementando as lacunas ou corrigindo as distorções encontradas nesses livros, destinando seu uso aos estudantes.

Concordamos que a produção de materiais alternativos seja essencial para dar suporte às mudanças necessárias na relação do professor com o livro didático (MEGID NETO; FRACALANZA, 2003), mas acreditamos que esses materiais podem ser mais do que recursos didáticos. Por isso, é necessário tomar cuidado para que essas sequências didáticas não sejam meros substitutos dos livros.

A mediação entre o conhecimento cotidiano e científico é uma habilidade que não pode ser simplificada segundo instruções de materiais didáticos. Pelo contrário, a criação de relações entre o contexto do aluno e os conceitos químicos, isto é, a contextualização do ensino, requer uma certa flexibilidade e autonomia do professor. A nosso ver, o desenvolvimento dessa capacidade advém de todo um conjunto que engloba os recursos didáticos disponíveis, a formação e a prática docente. A questão que queremos discutir, portanto, é como auxiliar o professor nessa tarefa de transformar seus saberes teóricos em práticos. 
Esse é um ponto de vista que não tem sido observado e discutido pelas pesquisas da área. Geralmente, o foco está em como transformar o conhecimento formal do aluno em científico, sem considerar o papel do professor nesse processo. Por exemplo, é comum encontrar trabalhos em que a contextualização dos conceitos químicos serve a propósitos de formação cidadã, por meio de uma abordagem Ciência, Tecnologia, Sociedade e Ambiente (CTSA) (GOMES; DIONYSIO; MESSEDER, 2015; HUSSEIN; FERNANDES; XAVIER, 2013; OLIVEIRA et al., 2011; SANTOS et al., 2012).

Esses trabalhos buscaram mostrar a importância da química em nossa sociedade e por quais razões compreendê-la é uma tarefa essencial. Entretanto, o que percebemos é que o conteúdo químico explorado não passa de um nível introdutório, isto é, professores acabam usando as temáticas do cotidiano sem discutir a fundo as relações entre elas e a química. Outras vezes, a contextualização é tratada como mero pano de fundo para as aulas tradicionais de química. Esse tratamento superficial da contextualização é percebido tanto na visão dos professores de química (SILVA; MARCONDES, 2010) quanto nos livros didáticos (WARTHA; FALJONI-ALÁRIO, 2005).

Por exemplo, a compreensão da estrutura atômica e das possíveis interações da matéria requisita dos alunos uma certa capacidade de abstração. Almeida e Santos Filho (2018) mostraram passo a passo como as interações moleculares explicam os processos de higiene no cabelo ao explorarem as interações existentes entre cabelo e xampu. A ênfase desse trabalho deve-se à minuciosa relação entre conteúdo químico e conhecimento cotidiano. Melhor dizendo, o conceito de interações intermoleculares foi detalhadamente construído a partir das experiências com higiene capilar dos alunos.

As interações intermoleculares podem ser amplamente discutidas utilizando-se os conhecimentos cotidianos dos alunos. Entretanto, ainda são poucos os trabalhos voltados para a contextualização desse conteúdo. A química, enquanto ciência da transformação da matéria, não pode ser ensinada ou aprendida sem que antes sejam bem construídas as formas pelas quais a matéria interage. Por esta razão, escolhemos o conteúdo de interações intermoleculares como nosso objetivo de ensino.

Para a contextualização desse conteúdo, nossa busca mostrou que a temática dos alimentos é frequentemente explorada em trabalhos de química ou ciências (CAÑAS; BRAIBANTE, 2019; CORREAA; SANTOS FILHO, 2016; SANTOS et al., 2016; TAHA et al., 2017; WIRZBICKI, ZANON, 2012). Contudo, esquece-se que os alimentos passam, necessariamente, pela boca, e nela ocorrem diversas reações químicas para processá-los. Além disso, as nossas sensações de sabor são causadas por diferentes formas de interações entre alimentos e a superfície da língua. Nesse sentido, essa temática ganha destaque em nosso trabalho, inclusive pela escassez de trabalhos similares.

Em síntese, todos nós sabemos que, a despeito dos esforços despendidos pelos professores de química, a educação não vai bem. Uma das razões para isso é a qualidade da formação de nossos professores. A orientação dos documentos oficiais é de que a contextualização do ensino tem o potencial de melhorar a aprendizagem dos nossos alunos. Do mesmo lado, os pesquisadores da área publicam inúmeros trabalhos dedicados a demonstrar os prós dessa abordagem. Todavia, o que percebemos é que dificilmente estes trabalhos estão preocupados em discutir o preparo dos professores para praticar a contextualização do ensino. O que há é uma falta de conexão entre todas essas esferas que, inevitavelmente, acaba sendo mais um peso nas costas dos professores. 
É nesse cenário que colocamos nossa estaca. A prática de contextualizar a química é um processo bastante complexo e que requer um certo suporte ou treinamento. Defendemos a produção de materiais alternativos, porém, não como substitutos dos livros, mas como materiais que tentem preencher algumas lacunas deixadas pela formação acadêmica, de modo a dar suporte à prática do professor.

Diante de tudo o que foi dito, desenvolvemos um material alternativo que contextualiza as interações intermoleculares a partir da experiência cotidiana de que os alimentos doces apresentam-se com diferentes graus de doçura (SANTOS FILHO; SANTOS, 2018). Este material foi aplicado em sala de aula e o presente artigo tem como objetivo último discutir as implicações do uso desse material alternativo na prática do professor, por meio dos resultados de aprendizagem dos alunos sobre esse conteúdo químico. Assim, a próxima seção apresenta a metodologia utilizada para pesquisa, seguida dos resultados e discussões da mesma, fechando com as conclusões e bibliografia.

\section{Metodologia}

A primeira parte dessa pesquisa consistiu no levantamento bibliográfico sobre os processos químicos e bioquímicos do paladar, especificamente, do gosto doce. Foram encontrados alguns trabalhos que tratam da estrutura molecular dos compostos capazes de evocar o sabor doce (DEUTSCH; HANSCH, 1966; FABER, 2006; KIER, 1972; LENT, 2002; MATHLOUTHI; PORTMANN, 1990; SHALLENBERGER; ACREE, 1967). Esses trabalhos investigaram a percepção química do gosto doce e, alguns deles, explicam como as modificações estruturais nas moléculas podem aumentar o poder adoçante evocado.

De posse dessas informações, pensamos em um caminho que, partindo das experiências cotidianas, levaria à a prendizagem dos conceitos científicos. Mais precisamente, desenvolvemos uma abordagem didática que, ao discutir o processo de percepção do sabor doce, constrói passo a passo os conceitos de ligação hidrogênio ${ }^{1}$ e interações de van der Waals. Para isso, foi preciso dar um tratamento didático às informações extraídas dos artigos científicos e da internet, de forma que as relações entre o científico e o cotidiano fossem devidamente estabelecidas. Esse foi o momento mais trabalhoso e importante da pesquisa, pois foi quando pudemos concretizar as nossas ideias sobre os novos caminhos que os professores podem tomar rumo à verdadeira contextualização.

Fazendo uma breve descrição do material, começamos pelo aspecto histórico da evolução humana, dos possíveis alimentos do homem e a relação com o paladar, da busca por temperos e como percebemos o sabor dos alimentos. Na sequência, partimos para a vivência das pessoas, sobre nossas experiências com os alimentos doces, que é o gosto com o qual mais estamos em contato.

Disso, afunilamos um pouco mais o assunto e entramos nos adoçantes naturais e artificiais. Iniciamos a análise estrutural das moléculas dos principais adoçantes que conhecemos comparando-as umas com as outras. Identificamos os grupos que pudessem ser os responsáveis por causar o gosto doce quando em contato com a língua. Para isso, também foi necessário discutir a estrutura molecular das proteínas que compõem a superfície da língua. Extraímos da internet as informações sobre as estruturas moleculares dos adoçantes naturais e artificiais, bem como das proteínas. Nesse ponto, já temos dois

${ }^{1}$ Nesse artigo optamos por usar o termo ligação hidrogênio, ao invés de ligação de hidrogênio. 
grupos de moléculas (adoçantes e proteínas) que interagem entre si (intermolecular) e podemos iniciar o entendimento de como se dá essa interação, sem que seja preciso utilizar as classificações e definições tradicionalmente encontradas nos livros didáticos.

Discutimos, no material, como as moléculas de adoçante interagem com as proteínas da superfície da língua por meio de duas ligações hidrogênio, sendo essa a condição básica para que o gosto doce possa ser sentido. Porém, a maior doçura evocada pelos adoçantes artificiais está relacionada com um terceiro ponto de interação entre molécula e receptor proteico. Os adoçantes artificiais, geralmente, possuem uma região que interage por forças de van der Waals com a cadeia carbônica comum às proteínas. Isso pode levar as moléculas de adoçantes a se ligarem mais fortemente à superfície da língua e, consequentemente, ficariam aderidas ali por mais tempo. Se pensarmos que exista uma relação entre o tempo de permanência das moléculas de adoçante na boca (antes que sejam engolidas) com a intensidade da doçura que causam, podemos supor que quanto mais tempo estiverem presas à língua, mais intenso será o sabor doce. Desse modo, os adoçantes artificiais seriam mais doces porque estabeleceriam diferentes interações com as proteínas da língua, e isso é conhecido como Triângulo da Doçura.

O material foi utilizado como referência para uma aula de interações intermoleculares em uma turma de Engenharia Química na Universidade Estadual de Campinas (Unicamp), em 2018. O professor responsável pela disciplina ministrou a aula de acordo com essa unidade didática. Ao final da disciplina, os alunos fizeram uma avaliação para obter a aprovação no curso, e essa avaliação continha uma questão discursiva sobre o conteúdo de interações intermoleculares e sobre a aula do sabor doce. Os nossos dados foram coletados a partir das respostas discursivas dos 40 alunos dadas para essa questão. A questão requeria que os alunos explicassem o que entendiam por ligação hidrogênio e forças de van der Waals e como essas forças podem unir as moléculas formando as substâncias que usamos cotidianamente.

A questão discursiva da avaliação requer um tipo de análise qualitativa e, para isso, utilizamos a técnica de Análise Textual Discursiva (ATD) como método de análise qualitativa e que é muito utilizado nas pesquisas em ensino (MORAES, 2003). Essa abordagem de análise visa construir novas compreensões sobre o fenômeno analisado, e se estabelece em três etapas: unitarização, categorização e comunicação. A unitarização consiste em desmontar todos os discursos analisados e, na sequência, deve-se organizá-los em categorias (categorização). As categorias produzidas nesse trabalho são ditas emergentes, pois foram criadas após a análise do corpus textual e estão listadas no quadro 1. Essas, por sua vez, serviram de base para a produção de metatexto (comunicação), que traz as conclusões da análise e o olhar do pesquisador sobre o novo emergente (MORAES, 2003). O metatexto resultante dessa análise encontra-se a seguir.

\section{Resultados e Discussão}

As categorias emergentes obtidas com a análise dos documentos textuais constam no quadro 1. Elas foram divididas em duas partes: uma para a ligação hidrogênio e outra para as interações de van der Waals. Cada uma das categorias recebeu um título que tem como função sintetizar as ideias por trás das unidades de sentido que as constituem. Nesse quadro também constam quantos documentos continham unidades de sentido identificadas em cada categoria, em termos percentuais. 
Quadro 1 - Categorias emergentes da análise do corpus

\begin{tabular}{|l|l|c|}
\hline \multicolumn{1}{|c|}{ Interação } & \multicolumn{1}{|c|}{ Títulos das categorias } & Percentual \\
\hline \multirow{4}{*}{ Ligação Hidrogênio } & 1. Condição especial do hidrogênio (H) para estabelecer a ligação hidrogênio & $82,50 \%$ \\
\cline { 2 - 3 } & 2. Natureza da espécie (Y) que interage com o próton do átomo de hidrogênio & $75,00 \%$ \\
\cline { 2 - 3 } & 3. Linearidade da ligação hidrogênio & $70,00 \%$ \\
\cline { 2 - 3 } & 4. Natureza eletrotástica da ligação hidrogênio & $57,50 \%$ \\
\cline { 2 - 3 } & 5. Ligação hidrogênio ocorre entre moléculas & $87,50 \%$ \\
\cline { 2 - 3 } Interações de van & 5.1 Associação com o tema sabor doce & $75,00 \%$ \\
\hline \multirow{5}{*}{ der Waals } & 7. Natureza das espécies envolvidas nas interações de van der Waals & $50,00 \%$ \\
\cline { 2 - 3 } & 7. Processo de formação dos dipolos & $57,50 \%$ \\
\cline { 2 - 3 } & $\begin{array}{l}\text { 8. Utilização dos argumentos de modelos teóricos para explicar a distribuição eletrô- } \\
\text { nica molecular }\end{array}$ & $52,50 \%$ \\
\cline { 2 - 3 } & 9. Como os dipolos interagem entre si & $62,50 \%$ \\
\cline { 2 - 3 } & 10. Interações de van der Waals ocorrem entre moléculas & $70,00 \%$ \\
\cline { 2 - 3 } & 10.1 Associação com o tema sabor doce & $45,00 \%$ \\
\hline
\end{tabular}

Fonte: elaborado pelos autores.

\section{Interpretação dos dados: o metatexto}

Essa análise gerou um número considerável de categorias e, por conta disso, esse metatexto sintetizou as ideias por trás da análise do corpus. As categorias 1 e 2 referem-se às condições para o estabelecimento da ligação hidrogênio. Começando pela categoria 1, percebemos que os alunos conseguiram explicar a condição especial em que o hidrogênio deve se encontrar para que a ligação hidrogênio possa ser estabelecida. As explicações dadas superaram aquelas definições simplórias e convencionais comumente encontradas nos livros sobre o assunto. A grande maioria dos alunos (82,50\%) conseguiu explicar, claramente, o processo que torna o próton do hidrogênio desprotegido ou descoberto, que é a condição primária para que o hidrogênio estabeleça a ligação.

O átomo de hidrogênio é um átomo que pode ser considerado diferente dos demais presentes na tabela periódica, pois possui 1 próton e 1 elétron. Devido a isso, há um fenômeno ímpar quando ele interage com outros átomos muito eletronegativos [...] assim, propomos um modelo para explicar a interação das espécies: quando o hidrogênio é ligado com espécies muito eletronegativas, os elétrons tendem a ficar deslocados na região da espécie mais eletronegativa. Esse fenômeno é acentuado de tal maneira, que a literatura afirma que há um próton 'pelado', pois, o próton proveniente do hidrogênio possui uma região 'sem cargas' ao redor. [Documento 9]. ${ }^{2}$

Esse trecho exemplifica um dos nossos resultados: os alunos começaram a pensar para além dessa restrição, não memorizando o famoso FON (flúor, oxigênio e nitrogênio), mas entendendo a interação de um ponto de vista microscópico. A compreensão de que é a deslocalização dos elétrons que determina a interação nos mostra que os alunos estimularam suas capacidades de abstração e generalização. Essas capacidades requereram que o aluno pensasse nas moléculas como um todo e identificassem

2Para preservar a identidade dos respondentes atribuiu-se uma numeração aos documentos que deram origem ao corpus. Além disso, todas as transcrições são fiéis aos documentos e não sofreram qualquer tipo de correção ou ajustes. 
os fenômenos eletrônicos que permitem a ligação hidrogênio. Diante disso, podemos argumentar que houve significativo nível de aprofundamento nos conceitos científicos.

A ligação hidrogênio pode ser considerada um caso especial das interações de van der Waals, pois é um caso extremo de atração dipolo-dipolo. Isso por causa de uma propriedade raramente discutida, que é o ponto trazido pela categoria 3. A linearidade é uma especificidade da ligação hidrogênio. Em 2011, a União Internacional de Química Pura e Aplicada (IUPAC) publicou um documento com novas recomendações sobre o assunto: "[...] the $\mathrm{X}-\mathrm{H} \cdots \mathrm{Y}$ angle is usually linear $\left(180^{\circ}\right)$ and the closer the angle is to $180^{\circ}$, the stronger is the hydrogen bond and the shorter is the HY distance [...] hydrogen bonds show directional preferences". (ARUNAN et al., 2011, p. 1638-1639).

Os resultados nos mostram que $70 \%$ dos nossos alunos fez referência à linearidade, sendo que deles, $30 \%$ usou explicitamente o termo linear e os outros $40 \%$ fez a representação gráfica da interação linear molécula-receptor ou da espécie $Y$ atacando o hidrogênio em um plano. O documento 26 contém a seguinte citação: "[...] a ligação hidrogênio, a qual é mais ou menos forte conforme sua angulação, sendo a conformação linear (180) a mais forte." $\mathrm{O}$ documento 21 diz: "[...] um próton descoberto e isso fará com que ele tenda a atrair qualquer densidade eletrônica sendo a situação mais favorável quando a aproximação for linear, pois há menor repulsão".

Quando o aluno fala em repulsão, está percebendo a ligação do ponto de vista eletrostático, gerando a categoria 4 . Dentre os resultados, $57,50 \%$ dos alunos usaram termos iguais ou similares à atração, tal como no documento 22: "[...] o próton do $H$, desprotegido, consegue atrair fortemente qualquer densidade eletrônica, condição que não ocorre em nenhum outro tipo de interação molecular"

Assim, para que o aluno entenda que essa interação é linear, ele precisa imaginar as moléculas e todo o fenômeno de deslocalização dos elétrons. Ao mesmo tempo, ele percebe que essa deslocalização é a causa das interações que são, basicamente, eletrostáticas. Toda essa interpretação é bastante abstrata. Isso exige um controle de pensamento e o uso de funções psicológicas superiores, que são evidenciadas pela verbalização e expressão desse pensamento, conforme mostram as citações.

A análise dessas quatro categorias nos leva a identificar uma quinta categoria: o aspecto intermolecular dessas interações. Nas categorias 1 e 2, está implícito que os alunos percebem a necessidade de duas espécies, com certas características, para a interação. A categoria 3 mostra que eles sabem que a interação mais forte ocorrerá quando essas duas moléculas interagirem linearmente. Além disso, a categoria 4 mostra que eles entendem essa interação sob uma perspectiva eletrostática. Consequentemente, está claro que os alunos compreenderam que esse tipo de interação ocorre entre moléculas.

Os resultados para essa categoria são otimistas, pois foi a categoria que obteve o maior percentual $(87,50 \%)$. As unidades que compõem a categoria revelaram que os alunos não confundiram interações entre moléculas com as ligações covalentes, conforme sugerem alguns trabalhos sobre concepções alternativas (COOPER; WILLIAMS; UNDERWOOD, 2015; FRANCISCO JR., 2008; KIND, 2004; MIRANDA; BRAIBANTE; PAZINATO, 2017; MOZZER; QUEIROZ; JUSTI, 2007; PETERSON; TREAGUST, 1989). 
Essa categoria, portanto, explicita a nossa constatação de que os alunos compreenderam que as interações intermoleculares são aquelas entre moléculas. Acreditamos que essa contribuição é positiva, visto o que tem sido relatado em trabalhos sobre concepções alternativas desse conteúdo químico. Nesse ponto, nossa pergunta foi: como podemos afirmar que essa contribuição está relacionada com o material utilizado pelo professor?

A análise dos dados expressa, claramente, que os alunos usaram o processo de percepção do gosto doce para explicar a ligação hidrogênio (subcategoria 5.1 do quadro 1). Os resultados mostram que $75 \%$ dos alunos mencionaram a interação entre moléculas e/ou fez a representação gráfica da molécula do adoçante interagindo com o receptor proteico da língua, conforme descreve o material.

Sabendo que o sabor doce é dado pela parceria de ligações $\mathrm{N}-\mathrm{H}, \mathrm{O}-\mathrm{H}$ e $\mathrm{C}=\mathrm{O}$, acontece o deslocamento de elétrons citado acima, dessa maneira, o próton desprotegido é ligado às estruturas da língua dando origem ao sabor doce. [Documento 25].

Esse tipo de interação promove atração e coordenação de moléculas [...] como o da interação açúcar/adoçante - proteína, que faz com que possamos sentir o gosto doce, que pode ser potencializado por interações do radical da proteína com outras partes do adoçante. Portanto, a presença desse tipo de interação é fundamental tanto no dia a dia quanto em situações de química aplicada e indústria. [Documento 23].

A partir das observações, pudemos concluir que o sabor doce não é proveniente de uma única espécie, mas de um conjunto de espécies em um arranjo único. Assim, concluímos que o sabor doce é esperado a partir de uma determinada parceria entre $\mathrm{N}-\mathrm{H}, \mathrm{O}-\mathrm{He} \mathrm{C}=\mathrm{O}$. $\mathrm{Na}$ língua, é conhecido (e foi apresentado em sala) que existem certos tipos específicos de aminoácidos, com estruturas como $\mathrm{N}-\mathrm{H}$ e $\mathrm{C}=\mathrm{O}$. Assim, propomos um modelo para explicar a interação das espécies. [...] O modelo apresentado é chamado de ligação hidrogênio. [Documento 9].

Na citação do documento 25, o aluno expõe a compreensão do aspecto eletrostático (categoria 4) e que o sabor doce é consequência dessa interação (subcategoria 5.1). 0 documento 23 expressa também a categoria 3, bem como a categoria 5 e 5.1, deixando claro que entende o sabor doce como resultante da interação entre uma molécula de adoçante e uma proteína da língua.

O documento 9 justifica, de forma breve, as razões para as observações que discutimos nesse artigo. Foi possível inferir através dos resultados que, ao compreenderem como se dá o processo de percepção do gosto, os alunos aprenderam que as interações intermoleculares ocorrem entre moléculas e as características necessárias para essas interações ocorrerem. Porém, entender essas características implica a mobilização de certas habilidades complexas, como a capacidade de abstração e generalização.

Assim, podemos dizer que o nosso objetivo de contextualizar o conteúdo de química em um nível mais aprofundado foi atingido, superando a mera exemplificação (WARTHA; SILVA; BEJARANO, 2013). A construção das relações entre conceito científico e cotidiano foi feita de forma bastante detalhada, passo a passo, considerando o processo pelo qual os conceitos cotidianos tornam-se mais elaborados. 
Considerando-se que a contextualização do conteúdo foi satisfatoriamente praticada, devemos, necessariamente, atribuir isso à mediação do professor. Tomando o nível de aprofundamento observado nas respostas dos alunos, podemos perceber que o professor conseguiu encontrar no nosso material uma boa forma de contextualizar o conteúdo. É claro que uma única intervenção não seria suficiente para que o professor aprendesse esse caminho e se tornasse autônomo no processo de mediação contextualizada. Todavia, a prática recorrente certamente o levaria a esse ponto.

Até aqui foram analisadas as cinco categorias para a ligação hidrogênio e, na sequência, são analisadas as demais categorias referentes às interações de van der Waals. Seguimos, basicamente, a mesma estrutura lógica usada para as ligações hidrogênio na criação das categorias sobre as interações de van der Waals.

$\mathrm{Na}$ categoria 6 enquadram-se todas as unidades de sentido que relataram as características das espécies envolvidas nas interações de van der Waals. Em função disso, selecionamos as unidades de sentido que mencionaram espécies ricas em elétrons, com insaturações alternadas ou com grupos $\mathrm{NH}, \mathrm{OH}$ e $\mathrm{CO}$ (que possuem elétrons livres). Reunimos nessa categoria todas as sentenças que indicam que os alunos entenderam que essas interações ocorrem em função dos elétrons (nas categorias a seguir outros aspectos serão considerados).

Podemos dizer que essa categoria é equivalente às categorias 1 e 2 , onde constam as informações sobre as características das espécies envolvidas na interação. Comparando-se os dados quantitativos delas, percebemos que mais da metade do número total de alunos apresentou as características para o estabelecimento da ligação hidrogênio (categorias 1 e 2), enquanto um número menor (50\%) fez alguma referência às características das moléculas envolvidas nas interações de van der Waals. As respostas, geralmente, começaram descrevendo como esse tipo de interação ocorre, ignorando as características das espécies.

Os resultados indicam que esse grupo de interações precisa ser trabalhado mais detalhadamente. Atribuímos a isso o fato de que as interações de van der Waals são um conjunto de interações diferentes (forças de Keesom, Debye e London) e que, portanto, deveriam ser discutidas uma a uma, bem como suas semelhanças e diferenças. Este é um ponto de melhoria que encontramos para o nosso material. Quando comparado à ligação hidrogênio, temos um número menor de respostas que drescrevem as características das espécies envolvidas na interação de van der Waals, contudo, esse percentual ainda é satisfatório.

Metade da quantidade total de alunos indicou que as espécies devem ser ricas em elétrons para que os dipolos sejam formados e, assim, estabeleçam interações de van der Waals. Isso pode ser exemplificado com as falas dos documentos 17 e 32, respectivamente: "[...] as forças de van der Waals podem ser descritas como ligações que se formam devido ao excesso/falta de elétrons em certa molécula, que interagem por dipolos" e, "[...] temos o que chamamos de forças de van der Waals, pois temos moléculas ricas em elétrons e é isso que faz com que os adoçantes artificiais sejam muito mais doces do que os naturais".

Essa última fala é interessante, pois mostra como os alunos associaram uma experiência do cotidiano - o fato de alguns adoçantes artificiais serem mais doces do que outros - com a existência de interações do tipo van der Waals entre as moléculas. Além do aspecto motivacional, os alunos podem, a partir do caso específico dos adoçantes, abstrair os aspectos gerais desse tipo de interação. 
Para tentar perceber se essa capacidade de abstração está, de alguma forma, sendo mobilizada pelos alunos, buscamos as unidades de sentido que constituem a categoria 8: que modelos teóricos foram utilizados para explicar a distribuição de elétrons nas moléculas?

Dos 40 respondentes, 57,50\% mencionaram a distorção na distribuição das cargas elétricas da molécula, onde uma parte torna-se mais negativa e a outra, mais positiva, gerando dipolos instantâneos. Selecionamos para essa categoria todas aquelas descrições adequadas ao processo de formação dos dipolos elétricos, tal como mostra o documento 17: "[...] molécula que numa fração de tempo, os elétrons dos orbitais ficam de um lado só, criando um dipolo instantâneo, fazendo com que hajam [sic] forças de van der Waals com outras moléculas".

Com esses dados, verificamos que pouco mais da metade da turma (52,50\%) explicou as interações de van der Waals usando, principalmente, os argumentos do modelo do orbital molecular. Usaram explicações como movimento dos elétrons nos orbitais moleculares e conjunto de orbitais moleculares deslocalizado por toda a molécula. Isso é interessante de ser notado, pois essas mesmas ideias não foram usadas para explicar a ligação hidrogênio. Na categoria 4 da ligação hidrogênio, a maioria das respostas $(57,50 \%)$ fundamentou-se em princípios eletrostáticos, a exemplo de próton atrai elétrons que não estão compartilhados e têm caráter eletrostático. Em síntese, percebemos que, para as ligações hidrogênio, os alunos percebem que as cargas são localizadas e que, para as interações de van der Waals, os elétrons estão em orbitais deslocalizados.

Acreditamos que aí exista uma lacuna conceitual e que poderia ser, de alguma forma, sanada com melhorias em nosso material ou pelo próprio professor. Em outras palavras, seria um ganho do ponto de vista intelectual dos alunos se fosse trabalhada a ideia de modelos teóricos e da relação entre eles.

A despeito do modelo teórico utilizado para explicar a formação de dipolos, a categoria 9 visou analisar como os alunos entendem a interação de dipolos entre si. Essa categoria obteve $62,50 \%$ das respostas, um número ligeiramente maior do que recebeu a categoria 7 (57,70\%), sobre o processo de formação dos dipolos. Isso nos mostra que os alunos conseguiram explicar como os dipolos são formados, mas podem ter tido um pouco mais de dificuldade para explicar como interagem entre si.

Um ponto relevante a ser mencionado está no fato de que 57,50\% dos alunos associaram, exclusivamente, as interações de van der Waals às forças de dispersão. Isto é, ao explicarem como os dipolos interagem entre si, fizeram-no restringindo essa descrição somente as forças de London. Em outras palavras, ao serem perguntados sobre interações de van der Waals, todos os alunos explicaram a formação e interação de dipolos instantâneos e induzidos. Atribuímos isso ao fato de que, as moléculas utilizadas como exemplo para esse caso, eram moléculas apolares.

A última categoria equivale, também, à categoria 5 para ligações hidrogênio, ou seja, trata das concepções alternativas e da natureza intermolecular dessas interações. Porém, fazendo uma comparação numérica entre ambas as categorias, notamos uma diferença de $17,50 \%$ em favor da categoria 5 . A categoria 10 obteve $70 \%$ das respostas, enquanto a categoria 5 alcançou 87,50\%. Apesar dessa diferença, devemos fazer uma observação importante: essa foi a categoria com o maior percentual para as interações de van der Waals. Isso indica que, apesar de uma incidência menor, mais da metade da quantidade total de alunos compreendeu que as interações de van der Waals ocorrem entre moléculas. 
E, somando-se a isso, a categoria 5 também foi a que obteve maior incidência percentual de respostas, o que pode indicar que a natureza intermolecular dessas interações foi fortemente demarcada nessa aula.

Da mesma maneira que fizemos para a ligação hidrogênio, devemos agora nos perguntar: como atrelar esses resultados à temática da aula? Para isso, geramos a subcategoria 10.1, que agrupou aquelas unidades de sentido que mencionaram a temática da aula. A análise das respostas mostrou que muitos alunos explicaram como ocorrem as interações de van der Waals usando os exemplos do adoçante interagindo com o receptor proteico da língua.

Além disso, estudamos o 'poder' de determinados adoçantes. [...] Assim, estudamos a molécula do aspartame (um dos adoçantes 'poderosos'). De acordo com sua estrutura, [...] possuía uma série de insaturações [...] geralmente dito como um 'sistema conjugado'. o que se imaginou foi que as espécies eletronegativas atraem mais os elétrons para si, mas não a ponto de deixar alguma espécie descoberta. Assim, esse pequeno incremento de carga se manifestava como um efeito dominó por toda a molécula [...]. A esse modelo foi dado o nome de forças de van der Waals [...]. [Documento 9].

O sabor doce é produzido dessa união do dipolo instantâneo (do adoçante) e do dipolo induzido (da língua). [Documento 25].

Aplicando as substâncias que usamos cotidianamente, temos o adoçante sintético, pois ele tem uma parte muito rica em elétrons que induz (dipolo induzido) a polaridade em outras moléculas (na língua) [que] podem se ligar a elas por esse tipo de interação (van der Waals). [Documento 17].

Para o seguinte adoçante sintético [desenhou a estrutura molecular da sacarina], há duplas alternadas, formando conjugados e por um instante de tempo muito pequeno pode ocorrer dos elétrons dos orbitais estarem só em um lado da molécula próxima a ela, formando um dipolo induzido e então há uma interação dipolo instantâneodipolo induzido, tornando o adoçante em questão mais doce. No geral, adoçantes ricos em elétrons são capazes de estabelecer forças de van der Waals explicada acima. [Documento 10].

O trecho destacado do documento 9 mostra que o aluno usa um determinado modelo teórico (categoria 8) para explicar como as espécies eletronegativas (categoria 6) formam os dipolos (categoria 7) e interagem entre si (categorias 9 e 10), associando tudo isso ao fenômeno de percepção do gosto doce (subcategoria 10.1). Podemos argumentar que a aprendizagem de conceitos mais complexos partiu da experiência cotidiana do aluno sobre os diferentes graus de doçura, agora explicados por meio da compreensão das interações de van der Waals.

Os demais trechos corroboram a ideia de que a construção do conceito científico é favorecida quando se parte do cotidiano. Isso foi atribuído ao fato de que os alunos preferiram utilizar o fenômeno do paladar para expressar suas ideias acerca do conceito químico. É importante ressaltar que os alunos foram solicitados a explicar o que entendiam por ligação hidrogênio e forças de van der Waals. Assim, por escolha deles, usaram o fenômeno do cotidiano para explicar um conceito bastante abstrato e complexo. 
Da mesma forma que para a ligação hidrogênio, podemos concluir que o professor atingiu seus objetivos didáticos, não só ensinando o conteúdo químico, como também conseguiu construir satisfatoriamente a relação entre conceitos científicos e cotidianos, o que nós entendemos que deve ser a contextualização do ensino.

\section{Considerações Finais}

Nosso trabalho concentra-se em produzir unidades didáticas temáticas que descrevam estratégias de como contextualizar determinados conteúdos químicos. Produzimos uma unidade didática sob a forma de texto que aborda as interações intermoleculares partindo da experiência cotidiana dos alunos sobre o sabor doce (SANTOS FILHO; SANTOS, 2018). O presente trabalho apresentou e discutiu os resultados da utilização desse material em uma aula sobre interações intermoleculares para os alunos de uma disciplina de química da graduação. Os dados foram obtidos a partir de uma questão discursiva sobre ligação hidrogênio e interações de van der Waals, e foram analisados segundo o método de Análise Textual Discursiva (ATD).

Os resultados mostraram que os alunos compreenderam que a ligação hidrogênio não ocorre exclusivamente com átomos de flúor $(F)$, oxigênio $(\mathrm{O})$ e nitrogênio $(\mathrm{N})$ como é comumente estabelecido. Aprenderam que a linearidade é uma característica que torna a ligação hidrogênio especial dentre as demais interações de van der Waals, e aprenderam sobre a natureza física dessa interação. Sobre as interações de van der Waals, os alunos souberam identificar as características das espécies envolvidas na interação. Os alunos utilizaram os argumentos dos orbitais moleculares para explicar como os dipolos são formados e também como interagem entre si.

Constatamos também que os alunos entenderam que ambos os tipos de interações ocorrem entre moléculas, isto é, que não confundiram as interações intermoleculares com as ligações covalentes que ocorrem entre átomos de uma mesma molécula, conforme demonstra a literatura (COOPER; WILLIAMS; UNDERWOOD, 2015; FRANCISCO JR., 2008; KIND, 2004; MIRANDA; BRAIBANTE; PAZINATO, 2017; MOZZER; QUEIROZ; JUSTI, 2007; PETERSON; TREAGUST, 1989). Esses resultados são sumariamente importantes, pois indicam que a estratégia que oferecemos em nosso material textual (SANTOS FILHO; SANTOS, 2018) favorece a construção de conceitos mais elaborados acerca das interações intermoleculares. Desse modo, acreditamos que estamos contribuindo para o processo de mudança dos atuais modelos de livros didáticos, mostrando ao professor novos caminhos e novos horizontes.

Acreditamos que a contextualização contribuiu para que os alunos não apresentassem as concepções alternativas reportadas pela literatura científica. Essa constatação vem do fato de que os alunos utilizaram o fenômeno do sabor doce para explicar as interações intermoleculares. Em outras palavras, o contexto cotidiano não atuou meramente como pano de fundo dos conceitos científicos, pelo contrário, os alunos utilizaram os conceitos científicos para complementar e enriquecer a compreensão das experiências cotidianas. Isso evidencia que o conhecimento científico não está distante da realidade dos alunos e eles podem começar a perceber as relações que existem entre ciência e sociedade.

Por fim, concluímos que a abordagem descrita na unidade didática que produzimos foi uma maneira apropriada e efetiva de ensinar os conceitos químicos. A estratégia contextualizada de abordagem das interações intermoleculares melhorou a aprendizagem dos conceitos científicos por sobrepujar as concepções alternativas previstas pela literatura. 
Com base nesse pressuposto, acreditamos que a produção de materiais com essas características e que contemplem essa estratégia didática deve ser estimulada e divulgada. Enxergamos grande relevância na produção de novos materiais auxiliares ao livro didático e na investigação de como esses materiais podem contribuir para a melhoria do ensino de ciências e formação de professores.

\section{Agradecimentos}

O presente trabalho foi realizado com apoio da Coordenação de Aperfeiçoamento de Pessoal de Nível Superior (CAPES), código de financiamento 001.

\section{Referências}

ALMEIDA, L. R.; SANTOS FILHO, P. F. A higiene capilar aplicada ao ensino de interações intermoleculares. Revista Brasileira de Ensino de Química, Campinas, v. 13, n. 1, p. 10-27, 2018.

AMORIM, F.; SOUZA, C. P.; TRÓPIA, G. Interdisciplinaridade, contextualização e pesquisa-ação: influências de um curso de formação continuada de professores de ciências na prática docente. Atos de Pesquisa em Educação, Blumenau, v. 5, n. 2, p. 189-208, 2010. Disponível em: https://tinyurl. com/ybdtkf8x. Acesso em: 23 jun. 2020.

ARUNAN, E. et al. Definition of the hydrogen bond: IUPAC recommendations 2011. Pure and Applied Chemistry, Oxford, v. 83, n. 8, p. 1637-1641, 2011.

BRASIL. Ministério da Educação. Diretrizes curriculares nacionais da educação básica. Brasília: Ministério da Educação, 2013.

BRASIL. Ministério da Educação. Parâmetros curriculares nacionais: ensino médio: bases legais. Brasília: MEC, 2000.

BRASIL. Ministério da Educação. Resumo técnico: resultados do índice de desenvolvimento da educação básica. Brasília: MEC, 2017a. Disponível em: https://tinyurl.com/y7gaxjvd. Acesso em: 20 jan. 2020.

BRASIL. Ministério da Educação. Sistema Nacional de Avaliação da Educação Superior. Relatório síntese de área: química: bacharelado/licenciatura. Brasília: MEC, 2017b. Disponível em: https:// tinyurl.com/ych4c9mk. Acesso em: 20 jan. 2020.

CAÑAS, G. J. S.; BRAIBANTE, M. E. F. A química dos alimentos funcionais. Química Nova na Escola, São Paulo, v. 41, n. 3, p. 216-223, 2019. DOI: http://doi.org/d2wd

COOPER, M. M.; WILLIAMS, L. C.; UNDERWOOD, S. M. Student understanding of intermolecular forces: a multimodal study. Journal of Chemical Education, Washington, v. 92, n. 8, p. 1288-1298, 2015. Disponível em: https://tinyurl.com/y82vq216. Acesso em: 4 jun. 2020.

CORRÊA, T. H. B.; SANTOS FILHO, P. F. Mão na massa: a química na panificação. Revista Brasileira de Ensino de Química, Campinas, v. 11, n. 1, p. 74-84, 2016.

DEUTSCH, E. W.; HANSCH, C. Dependence of relative sweetness on hydrophobic bonding. Nature, London, v. 211, n. 5044, p. 75, 1966. DOI: https://doi.org/10.1038/211075a0. 
FABER, J. Avanços na compreensão do paladar. Revista Dental Press de Ortodontia e Ortopedia Facial, Maringá, v. 11, n. 1, p. 14, 2006. DOI: http://doi.org/b3372g.

FERNANDES, C. S.; MARQUES, C. A. A contextualização no ensino de ciências: a voz de elaboradores de textos teóricos e metodológicos do Exame Nacional do Ensino Médio. Investigações em Ensino de Ciências, Porto Alegre, v. 17, n. 2, p. 509-527, 2012. Disponível em: https://tinyurl.com/yde2t5yx. Acesso em 2 jul. 2020.

FRANCISCO JR., W. E. Uma abordagem problematizadora para o ensino de interações intermoleculares e conceitos afins. Química Nova na Escola, São Paulo, n. 29, p. 20-24, 2008. Disponível em: https://tinyurl.com/yb3uj6fc. Acesso em 2 jul. 2020.

GOMES, L. M. J. B.; DIONYSIO, L. G. M.; MESSEDER, J. C. Análise de rótulos de produtos domissanitários como forma de discutir a química no cotidiano dos estudantes. Educación Química, México, v. 26, n. 1, p. 21-25, 2015. Disponível em: https://tinyurl.com/ycnyaoga. Acesso em 2 jul. 2020.

HUSSEIN, F. R. G. S.; FERNANDES, T. C.; XAVIER, C. R. A utilização do tema drogas para um ensino interdisciplinar e contextualizado de funções orgânicas. Enseñanza de las Ciencias: revista de investigación y experiencias didácticas, Barcelona, p. 2907-2912, 2013 (Número extra). Disponível em: https://tinyurl.com/ybeyj892. Acesso em 2 jul. 2020.

KATO, D. S.; KAWASAKI, C. S. As concepções de contextualização do ensino em documentos curriculares oficiais e de professores de ciências. Ciência \& Educação, Bauru, v. 17, n. 1, p. 35-50, 2011. DOI: http://doi.org/bvk9qw.

KIER, L. B. A molecular theory of sweet taste. Journal of Pharmaceutical Sciences, Easton, v. 61, n. 9, p. 1394-1397, 1972.

KIND, V. Beyond appearances: students' misconceptions about basic chemical ideas. London: Royal Society of Chemistry, 2004. Disponível em: https://tinyurl.com/yahqushx. Acesso em 2 jul. 2020.

LENT, R. Os sentidos químicos. In: LENT, R. Cem Bilhões de neurônios?: conceitos fundamentais de neurociência. 2. ed. Curitiba: Atheneu, 2002. p. 352-365.

LIMA, J. F. L.; PINA, M. S. L.; BARBOSA, R. M. B.; JÓFILI, Z. M. S. A contextualização no ensino de cinética química. Química Nova na Escola, São Paulo, n. 11, p. 26-29, 2000. Disponível em: https:// tinyurl.com/y747j5wm. Acesso em 2 jul. 2020.

LOPES, A. C. Os parâmetros curriculares nacionais para o ensino médio e a submissão ao mundo produtivo: o caso do conceito de contextualização. Educação \& Sociedade, Campinas, v. 23, n. 80, p. 386-400, 2002. Disponível em: https://tinyurl.com/y8ekh7m8. Acesso em 2 jul. 2020.

MATHLOUTHI, M.; PORTMANN, M. O. Hydrogen-bonding and the sweet taste mechanism. Journal of Molecular Structure, Amaterdam, v. 237, p. 327-338, 1990.

MEDEIROS, M. A.; LOBATO, A. C. Contextualizando a abordagem de radiações no ensino de química. Ensaio, Belo Horizonte, v. 12, n. 3, p. 65-84, 2010. DOI: http://doi.org/dz8k.

MEGID NETO, J.; FRACALANZA, H. O livro didático de ciências: problemas e soluções. Ciência \& Educação, Bauru, v. 9, n. 2, p. 147-157, 2003. DOI: http://doi.org/bmxj35.

MIRANDA, A. C. G.; BRAIBANTE, M. E. F.; PAZINATO, M. S. Concepções alternativas sobre forças intermoleculares: um estudo a partir das publicações da área de ensino. Enseñanza de las Ciencias, Barcelona, p. 1807-1812, 2017. (Número extra). Disponível em: https://tinyurl.com/ydxcrqpp. Acesso em 2 jul. 2020. 
MORAES, R. Uma tempestade de luz: a compreensão possibilitada pela análise textual discursiva. Ciência \& Educação, Bauru, v. 9, n. 2, p. 191-211, 2003. DOI: http://doi.org/dv5vc4.

MOZZER, N. B.; QUEIROZ, A. S.; JUSTI, R. S. Proposta de ensino para introdução ao tema interações intermoleculares via modelagem. In: ENCONTRO NACIONAL DE PESQUISAS EM EDUCAÇÃO EM CIÊNCIAS, 6., 2007, Florianópolis. Anais [...] Florianópolis: UFSC, 2007.

OLIVEIRA, A. G. S.; OLIVEIRA, C. G.; MATOS, R. A. F.; VAZ, W. F. Os sachês de catchup e maionese como tema gerador no ensino de funções químicas inorgânicas. Revista lberoamericana de Educación, Madrid, v. 56, n. 4, p. 1-9, 2011. DOI: https://doi.org/10.35362/rie5641504.

PETERSON, R. F.; TREAGUST, D. F. Grade-12 students' misconceptions of covalent bonding and structure. Journal of Chemical Education, Washington, v. 66, n. 6, p. 459, 1989.

RICARDO, E. C. Competências, interdisciplinaridade e contextualização: dos parâmetros curriculares a uma compreensão para o ensino das ciências. 2005. Tese (Doutorado em Educação) - Universidade Federal de Santa Catarina, Florianópolis, 2005.

SANTOS, D. G.; BORGES, A. P. A.; BORGES, C. O.; MARCIANO, E. P.; BRITO, L. C. C.; CARNEIRO, G. M. B.; EPOGLOU, A.; NUNES, S. M. T. A química do lixo: utilizando a contextualização no ensino de conceitos químicos. Revista Brasileira de Pós-Graduação, Brasília, v. 8, n. 2, p. 421-442, 2012.

SANTOS, P. M. L. et al. Análise de alimentos: contextualização e interdisciplinaridade em cursos de formação continuada. Química Nova na Escola, São Paulo, v. 38, n. 2, p. 149-156, 2016.

SANTOS FILHO, P. F.; SANTOS, M. C. O sabor doce e as interações intermoleculares. Revista Brasileira de Ensino de Química, Campinas, v. 13, n. 2, 2018.

SHALLENBERGER, R. S.; ACREE, T. E. Molecular theory of sweet taste. Nature, London, v. 216, p. 480482, 1967.

SILVA, E. L. DA; MARCONDES, M. E. R. Visões de contextualização de professores de química na elaboração de seus próprios materiais didáticos. Ensaio, Belo Horizonte, v. 12, n. 1, p. 101-118, 2010.

TAHA, M. S.; JAVORSKY, A. S.; VIÇOSA, C. S. C. L.; SOARES, E. L.; SAWITZKI, M. C. Valor nutricional dos alimentos: uma situação de estudo à contextualização e interdisciplinaridade no ensino de ciências. Góndola: enseñanza y aprendizaje de las ciencias, Bogotá, v. 12, n. 2, p. 131-141, 2017. DOI: http:// doi.org/dz8m.

VYGOTSKY, L. S. Pensamento e linguagem. 5. ed. São Paulo: Martins Fontes, 1995.

WARTHA, E. J.; SILVA, E. L.; BEJARANO, N. R. R. Cotidiano e contextualização no ensino de química. Química Nova na Escola, São Paulo, v. 35, n. 2, p. 84-91, 2013. Disponível em: https://tinyurl.com/ ybmupz5h. Acesso em: 1 jul. 2020.

WARTHA, E. J.; FALJONI-ALÁRIO, A. A contextualização do ensino de química através do livro didático. Química Nova na Escola, São Paulo, v. 22, p. 42-47, 2005.

WIRZBICKI, S.; ZANON, L. Abordagens e reflexões sobre o ensino do conceito energia nas transformações dos alimentos. Alexandria, Florianópolis, v. 5, n. 3, p. 195-218, 2012. 